\title{
Suggestibility And Its Relationship To Emotional Thinking Among University Students
}

\author{
Mohamed Abbas Mohamed ${ }^{1}$, Sufyan Saeb Salman², Natik Fahal Al-Kubaisy ${ }^{3}$ \\ Educational and Psychological Research Center/ University of Baghdad 1,2,3 \\ Email: algburimohammed@yahoo.com,_Al_maddidi@yahoo.com,dr.natik@yahoo.com
}

\begin{abstract}
Identifying the level of suggestibility and emotional thinking among university students is the key aim of this research, as well as identifying the significance of differences according to gender (males - females), and the correlation between the two variables. In order to verify this, the researchers adopted the measure of suggestibility prepared by "Roman Kotov" (2004), Arabized by (Abdul Rahman 2014), where the number of its final paragraphs reached (79) paragraphs, and adopted the scale of emotional thinking prepared by Abdullah 2017). The scale consisted of (27) final paragraphs, and their psychometric characteristics were ascertained, where the two tools were applied to a sample of (160) male and female students who were selected in a stratified random method from four colleges at the University of Baghdad: (College of Political Science and College of Education / Ibn Rushd, College of Engineering, and College of Science), for the academic year 2019-2020. The results of the research showed the following:

1. University students do not have a tendency to suggestibility.

2. There are no differences between (males and females) in suggestibility.

3. University students have emotional thinking.

4. There are no differences between (male and female) in emotional thinking.

5. There is no correlation between suggestibility and emotional thinking among university students.
\end{abstract}

Keywords:

Suggestibility, Emotional Thinking, University Students.

Article Received: 18 October 2020, Revised: 3 November 2020, Accepted: 24 December 2020

\section{Chapter 1}

Research problem:

The recent developments, technological advancements and the huge cognitive knowledge in various fields of human and scientific sciences, despite the increasing interest in cognitive strategies, and the development of higher mental capacity skills among students in educational stages, many psychological phenomena have emerged that play a major role in influencing the attitudes and behaviors of individuals. Among these phenomena is the phenomenon of suggestibility, which is noticeably increasing in size, clarity of danger and magnification for members of society in general and students in particular. It expresses the existence of a general willingness or tendency of many individuals to quickly ratify and accept the ideas, opinions, attitudes and beliefs of others in a way that lacks critical thinking and insight in various matters. Therefore, their behavior is often illogical, and these people are often victims of rumors, myths, and destructive messages broadcast by many satellite channels and other print and audio media (Muhammad, 1999,: 392)

On the other hand, education scholars throughout the ages have been interested in researching the topic of thinking and studying its skills as an individual cognitive process that includes a series of mental activities that the human brain undertakes when the individual seeks to solve a problem or explain an ambiguous situation. This interest has resulted in the establishment of many theories that explain thinking and dealt with his skills and attitudes or various approaches to his teaching.

Affective thinking is one of the types of negative thinking that depends on the experiences that the individual is going through, and the emotions, sensations and feelings it contains, as these emotions distract him and dominate his thinking, as he explains matters without an 
objective look and leads to disastrous results that affect his achievement and his academic level (Abdul Rahim (2011: 206). This study was based on what the Iraqi society is experiencing from a critical and difficult period on all political, economic, educational and health levels, as well as the wide range of conflicting media in the accuracy of conveying facts and the abundance of social media sites, which have a great impact as researchers believe on opinions, trends and beliefs and the ideas of community members in the shadow of the psychological climate in which they live. The research problem arises by answering the following question: Is there a relationship between suggestibility and emotional thinking among university students?

\section{Research importance:}

The researcher's and student's interest in the fields of psychology has increased at the undergraduate level because it is one of the basic stages of the social and cognitive interaction of individuals. It is in essence the outcome of biological factors, in addition to being a stage for the growth of capabilities, abilities, attitudes, personal relationships, emotional growth, and professional interests. The phenomenon of suggestibility is one of the means by which the individual acquires the prevailing standards in society, those standards that represent the frame of reference that are referred to from time to time, and there are attitudinal factors that make the individual influenced by the judgments of others.

That is, this influence does not occur as a result of a single experience, but as a result of exposure to interaction in a social situation. That is, the individual's perception of the situation and the interpretation that he gives of the elements of this situation determines the type and degree of being affected by it. The group constitutes pressure on the individual, causing him to change his rulings towards the group towards rulings that may be correct or incorrect according to the requirements of the situation (Al-Daghestani, 1995: 31). The side effects of accepting negative thoughts from others, if it is reflected in the life of the student, will affect their academic performance and define their personal identity inside and outside the university.

Therefore, we find that many studies dealt with many psychological variables to preserve the integrity of the students 'psychological structure, in a way that achieves a balanced and successful personality for them.

The male or female student while living the interaction process, a number of situations arise before them that make them face problems that require them to find a solution that facilitates the process of interaction and consensus (Hussein and Abdul-Jabbar, 2000: 144).

The topic of thinking has received the attention of many researchers and educators so that it has become one of the most studied and researched topics in the field of educational psychology. All philosophical, intellectual and educational schools have been concerned with the development of thought and thinking, so that the individual becomes more able to face the difficulties and problems that stand in his way in the various aspects of life. The thinking process is of great importance in a person's life, as it enables the person to solve his problems, to understand and comprehend the introductions, causes and consequences of many life situations, and to put in place the necessary treatments appropriate to a number of difficulties, individual and social dilemmas (Al-Tamimi, 2014: 50) It is a mental activity by which we acquire knowledge, solve problems, and our behavior appears most logical and rational, and with it we discover from knowledge what secures for us control over the world in which we live (Al-Shantawi, 1990: 49).

Among the types of this human activity is emotional thinking, and this type of thinking is negatively related to the prediction of success in life, and it is related to low emotions, inability to control stress and difficulties in life, communication skills, due to distorted perception of others, and low impulse control. Emotional thinking is associated negatively with general intelligence, balanced mood, social competence, 
tendency to accomplish, goal-directing, selffulfillment, compatibility, and honesty as well (Mehrabian, 2000: 133-239). Gazaniga 2001 noted that emotional-minded people struggle to appreciate the situations and consequences resulting from them, and they also find it difficult to deal with the pressures and problems they face in life, as they are the most problematic for themselves and others (Gazaniga, 2001: 124,Alakrash et.al 2020).

The importance of the current research lies in the sample that will be studied, who are university students, as well as the variables of suggestibility and emotional thinking that have not been previously studied together (according to the knowledge and knowledge of the researchers). Therefore, this study aimed to identify the extent to which the variables are related to each other and whether university students have a capacity for attractiveness or emotional thinking through the current study.

\section{Research objectives: to identify:}

1. The level of suggestibility among university students.

2. The significance of the difference in suggestibility according to the gender variable (male-female) among university students.

3. The level of emotional thinking among university students.

4. The significance of the difference in emotional thinking according to the gender variable (malefemale) among university students.

5. The correlation between suggestibility and emotional thinking among university students.

\section{Research limits:}

The current research is limited to students of Baghdad University, for both genders (malefemale) and (scientific-human) major for the academic year 2019-2020.

\section{Defining terms:}

First: Suggestibility:

Kotov (2004)
The individual's desire that his thoughts, opinions and beliefs correspond to the ideas, opinions and beliefs of others, without examination or scrutiny (Kotov, 2004: 66).

Al-Khalidi (2008)

The desire to imitate and conform to accepting ideas while losing the critical view and the ability to evaluate, and easily influenced by commercial advertisements (Al-Khalidi, 2008: 133).

Theoretical definition: Through the aforementioned definitions, the researchers adopted the definition of "Kotov" a theoretical definition of the current research, as the researchers have adopted its scale.

Procedural definition: the total score that the respondent obtains on the scale of suggestibility in the present research

Second: Emotional Thinking:

Damasio, 2000:

A style of hasty thinking that is characterized by being affected by situations emotionally and weak in the ability of the individual to solve problems, which leads to a weakness in dealing with different situations (Damasio, 2000: 145).

Theoretical definition: Since the researchers have adopted Damasio's point of view, the theoretical definition is Damasio's 2000 definition mentioned above.

Procedural definition: the score obtained by the respondent by answering the emotional thinking scale in the current research.

\section{Chapter II}

The theoretical framework and previous studies

\section{First: Suggestibility:}

The concept of suggestibility is one of the concepts that did not receive the attention of researchers and scholars in the fields of psychology except in the second half of the twentieth century, which may play a major role in forming our attitudes and emotions towards opinions, ideas, beliefs and social systems, especially if they are issued by prominent personalities or influential or was embraced by a large number of people. We absorb 
the traditional opinions, trends and beliefs common in our group without criticism or analysis, especially those that prevail in the family atmosphere that arise in its arms, such as the family's attitudes toward religion, homeland, and the social or economic system, and our attitudes towards right and wrong. The family is not the only source for what we gain from trends through appetite, there is school, the press, radio, propaganda, private reading, opinions of opinion leaders, and opinions and ideas we hear from our friends and colleagues (Abd al-Rahman, 2014: 25).

\section{Factors affecting suggestibility:}

The studies of Ofshe and Snicker (Ofshe \& Singer, 1986) indicated that environmental determinants, social pressure, and the influence on cognitive representations of a person are among the basic factors that can help in accepting the prejudice, by means of which ideas, attitudes and beliefs are modified and formed, as well as the existence of individual differences in acceptance and influence by others. The degree of suggestibility varies from one person to another, and these differences appear in the following points:

1. The ability to control the environment and the environment varies from each other. There are two cases, the first that depends on confinement and isolation, while the second focuses on the person's social and natural environment in terms of interaction with family, peers and in the work environment.

2. A state of altered consciousness, as it is used in the case of group therapy, hypnosis and meditation, by exploiting the state of weakness, dependence and amplification.

3. Methods of suggestibility have multiple forms, including physical, rewards, punishment, or intimidation, or it may be through emotional dialogue and dealing with failure and guilt, low self-esteem and personal failure (Abdullah, 2003: 205).

\section{Types of suggestibility:}

1. Positive as opposed to (negative) antisuperiority:

The affected person in the case of positive suggestibility accepts the influencer's idea without criticism or scrutiny, whereas in the oppositional suggestibility, the affected does not accept the influencer's idea, and the degree of readiness to counter-suggestibility varies from one person to another, and in one person from one situation to another, or from time to time .

2. The individual suggestibility versus the collective suggestibility:

In the individual suggestibility, the affected person is based on an individual basis, while the collective suggestibility is in it the affected person is an individual within a group.

3. Suggestibility of behavior versus suggestibility for speech:

In behavioral apprehension, the affected person believes in his idea and his behavior without intention. As for the temptation to speak, the idea he has may not be more than just a verbal expression, which may be superficial and has no effect on the behavior, which makes him sometimes appear on something contradictory, for lack of congruence between his behavior and his words. $\mathrm{He}$ is most often unaware of this contradiction.

Some psycho-social perspectives in explaining the concept of suggestibility:

In Freud's viewpoint (Freud, 1856-1939), the suggestibility is a general innate tendency that expresses the motive of individuals for submission. It appears clearly in humans since childhood and resides in what he calls the "Supreme Ego" that develops in the child as a result of his assuming the role of his father, who is of the same sex, in an attempt by the child to solve the Oedipus complex in males and the Electra complex in females.

Within the framework of this motivation come the individual's thoughts, feelings, and actions according to the thoughts, feelings, and actions of another individual or other individuals (Abu Hatab and Sadiq, 2000: 741). Horney (18851952) asserts that there are innate differences 
between people, but she did not pay attention to that. She considered human behavior an educated behavior, and that by adopting submission, the person tries to achieve security and contentment for him. Horney paid great attention to the effect of the environment on behavior, and she emphasized that suggestibility appears as a result of the motive of submission, and the tropical person is that compliant with the majority in his world, who is coordinated in the stream of crowds, as he always seeks sympathy and approval, and does not disagree, and avoids criticism from others. He always obeys and obeys, so Horney calls it the subserviently submissive type who seems to tell himself if I obey I will not be harmed (Muhammad, 2002: 56).

Levin 1890-1947 believes that there are powerful psychological forces called (directed force). Thus, it emphasizes the role of social relations in reclamation. (Masoud, 2011: 2-6).

As for Bandura and Walters (1963), scholars of social learning theory have interpreted seduction as being literate, and it is through the process of forming ideas and beliefs through imitation and imitation. Ideas and beliefs are learned by the individual, just like personal habits, according to a social model, and by simulation. Ideas and beliefs are learned through the methods of observation of the model that performs them as a result of their repeated saturation of its objectives tends to be used in similar situations, and learning is called observation, imitation, or model learning (i.e. modeling) (Qatami, 1998: 169-170).

\section{Social comparison theory:}

This theory was compiled by the American psychologist Leon Festinger (1954), in which he emphasized the effect of social interaction through opinions and trends. Then, it included an assessment of each of the capabilities, ideas and opinions. (Festinger developed this theory before his theory of cognitive dissonance). Therefore, some ideas in both may be similar, in both of them he emphasized the role of cognitive processes on the concept of consistency, as individuals are automatically driven to match their opinions with the views of others within the group to which they belong, and in the meantime, they undergo multiple variables to fulfill their desires to create a kind of The harmony between them and those around them (Insko, 1967: 20). Festinger believes that communication or social interaction has an effect on opinions, trends and capabilities, as some competitive behavior and processes of social influence are due to the need to evaluate oneself through others. Individuals choose people who do not differ with them in opinions and trends, and this is a type of internal consistency.

When differences occur within groups, there is pressure towards consistency, for example when you disagree with a friend on a specific social issue, such as flattering an enemy that leads him to shift his opinion to conformity with you. Festinger can interpret this phenomenon as occurring according to the motive of comparison, since a friend cannot be different from his friend in opinions, directions, or dimensions closely related to the subject of friendship. Since the calendar is a social necessity, the friend seeks social comparison to correct his opinion, and the pressure towards consistency causes a shift in the friend's opinion in order to bring the matter close to you, or he may realize that there is a difference, which leads to a threat to the relationship with loss (Kassin \& Fein \& Markus, 2011: 240-242, Elaf \&Hussien 2020). The researchers adopted Festinger's point of view because it emphasized social interaction through opinions, attitudes, assessment of capabilities and ideas, and was consistent with the objectives of the current research.

\section{Second: The Emotional Thinking}

Affective thinking refers to the general lack of ability to distinguish between emotions and thoughts, as strong emotions sometimes tend to interfere with balanced intellectual processes. This may produce distorted views of relationships and attitudes, and this type of thinking is negatively related to predicting success in life, and is associated with reduced impulsivity, inability to 
control stress, life's difficulties, and communication skills. Because of the distorted perception of others, reduced impulse control, emotional thinking is negatively associated with general intelligence, balanced mood, social competence, tendency for achievement, goalorientation, self-fulfillment, conformity, and honesty (Mehrabian, 2000: 233- 239).

This type of thinking is represented by the cognitive response based on the emotional experience of the individual (Al-Rimawi et al., 2008 , 22). It is the opposite of neutral thinking based on objectivity, as it is based on the emotions and feelings that lie in the depth, as well as on intuition of where the sudden understanding, or sudden vision of a specific situation, and there are a group of things that the owner of this type of thinking focuses on: -

Show feelings and emotions, such as: pleasure, confidence, anger, suspicion, jealousy, fear, hate, love ... etc. Interest in feelings only, without facts or information.

Rejection of facts or opinions without a rational justification, but rather on the basis of feelings and feelings.

- Always characterized by prejudice, and guesswork tilted to the irrational human side

The emotional thinking allows the transition from one emotional state to another in moments rather quick. Thinking can change emotions, and it is the perceptual, sensory part of thinking, not the logical part of it. If we see something in a different way from a previous time, then our emotions perception may change. Likewise, it is a pattern of thinking that depends on the experiences that the individual has gone through, and the feelings they carry, distort, and controlled by self-emotions and emotions (De Bono, 2001: 105).

\section{Damasio's theory of emotional thinking:}

Damasio described emotion as an internal nervous state, or an unconscious neurological reaction to a specific stimulus due to nerve activation in the brain. Since these nerve activities are often a result of the individual's internal emotional state, the body will adapt to an external emotional state ( Damasio, 2000: 133). Situations in the external environment are patterns of activation of the receptor cells of the retina, and those retinal patterns are processed serially and in parallel; to extract visual elements that patterns perceive in the outside world, and relate to patterns of nerve cell activity in the brain. Those neural patterns are called perceptual representations. Therefore, thinking is done by means of the neuronal activation patterns of the cell. Damasio has suggested that the senses of hearing, sight, touch, taste, and smell operate by patterns of nerve activation that correspond to the state of the outside world. Examples of these patterns are emotions (Charlton, 2000: 1-4).

Perhaps the most fertile of Damasio's ideas, which have a major influence, is the idea of the mechanism of the physical influence, which forms the basis of human consciousness, and it is the way in which perceptual representations of the external world interact with perceptual representations of the internal world, as thinking interacts with emotions. As this mechanism assumes that thinking and emotion are intertwined in an inseparable way, especially what affects planning and decision-making, $\mathrm{He}$ also explains that the expression of the physical response precedes the feeling of it. If the individual is aware of that feeling, it would be the additional step in the process, and differs from having the feeling alone (Damasio, 1995: 126, Alakrash et al.2020).

Damasio and his colleagues believed that the critical factors in social cognition that include logic, planning, and decision-making are closely related to emotion, and he emphasized the critical role of culture and cognition in shaping emotional experience. Damasio's theory is based on the correlation of three main processes: the perception of the appropriate stimulus, which is called (the target of the emotional component), the nervous representation of the body, and the neural representation of the self or consciousness. According to Damasio, these components do not 
mix, but merge side by side, although Total experience is integrated. Based on Damasio's opinion, emotion refers to the complex set of chemical and neural responses that constitute a modification of the body's balance, as the process requires coordinated nervous activity that includes mental images, processing the appropriate stimulus on the conscious perception of feeling from the body, and alterations in the self (Damasio, 2003: 53)).

The relationship between emotion and reasoning that Damasio explained according to the neurological aspects, which includes clear cases of emotional weakness, patients with severe damage in the main areas of excitability also failed to perform well in tasks that included risk assessment (Damasio, 1995: 126). The researchers have adopted the Damasio theory because it provides an overview of the variable from several biological, cognitive and emotional dimensions, which enables researchers to provide a comprehensive understanding of it in order to reach the goal of the research.

\section{Chapter III}

Research methodology and procedures

First: The research community: The research community consisted of students from Baghdad University for the academic year 20192020 , as their number reached $(55,317)$ distributed among (24) scientific and humanitarian colleges, and according to the gender variable by (26197) males and $(29,120)$ females.

Second: The research sample: The researchers adopted the selection of their research sample on the stratified random method, as the number of the sample members reached (160) students who were selected from four colleges at the University of Baghdad: Engineering and the College of Science), distributed according to the faculty and gender variables, and Table (1) illustrates this.

Table (1)

The basic research sample is distributed according to the faculty and gender variables.

\begin{tabular}{|c|c|c|c|c|}
\hline \multirow{2}{*}{ Total } & \multicolumn{2}{|c|}{ Type } & College & \multirow{2}{*}{} \\
\cline { 2 - 4 } & Females & Males & & \\
\hline 41 & 22 & 19 & Political Science & 1 \\
\hline 48 & 25 & 23 & $\begin{array}{c}\text { Education / Ibn } \\
\text { Rushd }\end{array}$ & 2 \\
\hline 37 & 20 & 17 & Engineering & 3 \\
\hline 34 & 18 & 16 & Sciences & 4 \\
\hline 160 & 85 & 75 & Total & \\
\hline
\end{tabular}

\section{Third: The research tools:}

In order to measure the variables of the current research which are (ability to suggestibility and emotional thinking), the researchers looked at some studies and measures related to the research variables, and after reviewing the literature on the concept of suggestibility, the researchers adopted the "Roman Kotov" scale (Kotov, 2004) ), expressed by (Abdul Rahman 2014),
As the original English version was translated and the veracity of the translation was extracted according to scientific and methodological steps in a way that suits the Iraqi environment,

The scale consisted in its final form of (79) paragraphs corresponding to three alternatives: (Completely agree, somewhat agree, disagree) offset by a scale of degrees $(1,2,3)$, this is for the positive paragraphs, as for the negative paragraphs, 
it is offset by a scale of degrees $(1,2,3)$. As for the (emotional thinking) scale, the researchers adopted the scale prepared by (Abdullah 2017), as the scale consisted of (27) paragraphs in its final form, corresponding to four alternatives: (Strongly agree, agree with a moderate degree, agree slightly, no I agree) and grades were assigned to it $(4,3,2,1)$ for positive paragraphs and $(1,2,3,4)$ for negative paragraphs. The scale was distributed into three domains, with (9) items for the behavioral domain, (9) items for the cognitive domain, and (9) items for the emotional domain.

\section{Validity of paragraphs (apparent truthfulness):}

For the purpose of identifying the validity of the paragraphs, the research criteria were presented to a group of specialists in education and psychology to determine the validity of the paragraphs of each measure, and in light of the opinions of specialists, the paragraphs that obtained an agreement rate of $80 \%$ or more were retained. Retain all paragraphs for both scales, with minor modifications.

Statistical analysis of the two scales items:

And since the two scales are modern and have fulfilled the conditions for the statistical analysis procedures and the conditions for building the psychological and educational scale. After the researchers discussed with some specialists in the field of measurement and psychological evaluation, their opinions were taken and they all agreed to extract the psychometric characteristics of the two scales, which are represented by (truthfulness and consistency) only, as follows:

\section{The psychometric characteristics of the two} scales: The ability to suggestibility and emotional thinking: Indicators of Validity Index

Validity is one of the basic characteristics of psychological scales because it indicates the ability of the scales to measure what was set up for measurement (Eble, 1972, P.408). The two current research measures had an apparent validity index, as follows: Face Validity: The apparent validity is a reference to what appears to be the scale to measure what was set for it, i.e. the extent to which it includes paragraphs that appear to be related to the variable being measured and that the content of the scale is consistent with its purpose. It is the general appearance of the scale in terms of the type of vocabulary, how it is formulated, and its clarity (Al-Imam, 1990, p. 130).

This type of validity was achieved in these two scales when the paragraphs of each scale were presented to a group of experts and specialists in education and psychology to judge their validity in measuring the characteristic to be measured. (As mentioned earlier).

\section{Reliability:}

The reliability of the two scales was verified by the following methods:

\section{Test-Retest Method:}

The researchers applied the two scales to a sample of (30) male and female students, randomly selected from the University of Baghdad without the main application sample, and the two scales were re-applied to the same sample after period of (14) days. The correlation coefficient between the first and second application was calculated using the Pearson correlation coefficient and the reliability coefficient was (0.77) for the suggestibility scale, and (0.78) for the emotional thinking scale.

Cronbach Alpha Method:

The Cronbach alpha equation was applied to the scores of the individuals of the first application of stability, and the reliability coefficient was $(0,81)$ for the scale suggestibility, and $(0,83)$ for the scale of emotional thinking.

Fourth: the final application sample:

After the researchers completed the two research tools and verified their validity and reliability, they applied them in one batch to the research sample (by presenting the two scales together to the subjects), whose number (160) students were randomly selected from four colleges at Baghdad University, as mentioned above.

Fifth: statistical methods: 
The researchers used the following statistical methods using the statistical program (spss):

- T-test for two independent samples.

- Pearson correlation coefficient.

The Alfa Cronbach equation.

- T-test for one sample.

- Percentage equation.

\section{The Fourth chapter}

Results review and discussion

The first objective: To identify the level of suggestibility among university students:
The results of the statistical analysis showed that the average of the sample scores for the suggestibility reached (150.95) with a standard deviation of (10.28), while the hypothetical average of the scale was (158), by using the t-test for a sample One, it appeared that the calculated $\mathrm{T}$ value was (-6.85) and when compared to the tabular value of (1.96) it was found that it was not statistically significant at the level (0.05) and with a degree of freedom (159), which means that the members of the research sample They do not have receptivity and Table (2) illustrates this.

Table (2)

The result of the t-test for the difference between the arithmetic and hypothetical mean of the research sample in the suggestibility.

\begin{tabular}{|c|c|c|c|c|c|c|}
\hline \multirow{2}{*}{$\begin{array}{c}\text { Significance } \\
(0,05)\end{array}$} & \multicolumn{2}{|c|}{ T-value } & \multirow{2}{*}{$\begin{array}{c}\text { Hypothetical } \\
\text { mean }\end{array}$} & \multirow{2}{*}{$\begin{array}{l}\text { Standard } \\
\text { deviation }\end{array}$} & \multirow{2}{*}{$\begin{array}{c}\text { Arithmetic } \\
\text { mean }\end{array}$} & \multirow[t]{2}{*}{ Sample } \\
\hline & Tabular & calculated & & & & \\
\hline $\begin{array}{c}\text { Non- } \\
\text { significant }\end{array}$ & 1,96 & $-6,85$ & 158 & 10,28 & 150,95 & 160 \\
\hline
\end{tabular}

The second objective: To identify the significance of the difference in the suggestibility according to the gender variable (males - females) among university students:

In order to achieve this goal, the average scores of both males and females were calculated separately from the other in the scale of (receptivity), as the average score for males was (149.53) with a standard deviation of (9.25), while the average score for females was $(151,74)$ with a standard deviation of (10.30). By using the T-test for two independent samples, it appeared that the calculated $T$ value was $(1,83)$ When compared with the tabular value of (1.96) it was found that there is no difference between males and females in suggestibility, at the level of (0.05) and the degree of freedom (158). Table (3) illustrates this.

Table (3)

T-test results of two independent samples between mean scores of males and females in suggestibility

\begin{tabular}{|c|c|c|c|c|c|c|}
\hline $\begin{array}{c}\text { Significance } \\
(\mathbf{0 , 0 5})\end{array}$ & \multicolumn{2}{|c|}{ T-value } & $\begin{array}{c}\text { Standard } \\
\text { deviation }\end{array}$ & $\begin{array}{c}\text { Arithmetic } \\
\text { mean }\end{array}$ & No. & Type \\
\cline { 2 - 6 } & tabular & calculated & & & & \\
\hline $\begin{array}{c}\text { Non- } \\
\text { significant }\end{array}$ & 1,96 & 1,83 & 9,25 & 149,53 & 75 & Males \\
\cline { 5 - 7 } & & & 10,30 & 151,74 & 85 & Females \\
\hline
\end{tabular}

The third goal: To identify the level of emotional thinking among university students: -

The results of the statistical analysis showed that the mean scores of the sample in emotional thinking were (76.72) with a standard deviation of (4.52), while the hypothetical average of the scale was (67.5). By using the T-test for one sample, it appeared that the value the calculated $\mathrm{T}$ was (10.03). When compared to the tabular value of (1.96) it was found that it was a statistically 
function at the level (0.05) and with a degree of freedom (159), which means that the individuals of the research sample have emotional thinking. The table (4) illustrates it.

Table (4)

The result of the T-test for the difference between the arithmetic and hypothesis average of the research sample in emotional thinking

\begin{tabular}{|c|c|c|c|c|c|c|}
\hline \multirow{2}{*}{$\begin{array}{c}\text { significance } \\
(\mathbf{0 , 0 5 )}\end{array}$} & \multicolumn{2}{|c|}{ T-value } & \multirow{2}{*}{$\begin{array}{c}\text { Hypothetical } \\
\text { mean }\end{array}$} & \multirow{2}{*}{$\begin{array}{l}\text { Standard } \\
\text { deviation }\end{array}$} & \multirow{2}{*}{$\begin{array}{c}\text { Arithmetic } \\
\text { mean }\end{array}$} & \multirow[t]{2}{*}{ Sample } \\
\hline & tabular & calculated & & & & \\
\hline significant & 1,96 & 10,03 & 67,5 & 4,52 & 76,72 & 160 \\
\hline
\end{tabular}

Fourth Objective: To identify the significance of the difference in emotional thinking according to the gender variable (male - female) among university students: -

To achieve this goal, the average scores of both males and females were calculated separately from the other on the scale of (emotional thinking). The average score for males was (76.46) with a standard deviation of (4.89), while the average score for females was (76) with a standard deviation of $(4,69)$. By using the T-test for two independent samples, it appeared that the calculated $\mathrm{T}$ value was (0.194). When compared with the tabular value of (1.96), it was found that there are no differences between males and females in emotional thinking, at a level (0.05) and a degree of freedom (158). Table (5) illustrates this.

Table (5)

Results of the T-test of two independent samples between the mean scores of males and females in emotional thinking

\begin{tabular}{|c|c|c|c|c|c|c|}
\hline $\begin{array}{c}\text { Significance } \\
(\mathbf{0 , 0 5})\end{array}$ & \multicolumn{2}{|c|}{ T-value } & $\begin{array}{c}\text { Standard } \\
\text { deviation }\end{array}$ & $\begin{array}{c}\text { Arithmetic } \\
\text { mean }\end{array}$ & No. & Type \\
\cline { 2 - 6 } & Tabular & calculated & & & & \\
\hline $\begin{array}{c}\text { Non- } \\
\text { significant }\end{array}$ & 1,96 & 0,194 & 4,89 & 76,46 & 75 & Male \\
\cline { 4 - 7 } & & & 4,69 & 76,08 & 85 & Female \\
\hline
\end{tabular}

Fifth Objective: Identify the correlation between suggestibility and emotional thinking among university students: -

After analyzing the results using the Pearson correlation coefficient, there is no correlation between the suggestibility and the emotional thinking of the sample as a whole. The value of the correlation coefficient was (0.091), which is smaller than the Pearson tabular value of (0.159), at the level of significance (0.05) and the degree of freedom (158).

\section{Recommendations:}

1. Encouraging students to assert themselves and independent opinion.

2. Instructing the teaching staff to be keen on testing students emotionally, to find out the weaknesses in their personalities, and to try to address them by achieving the correct compatibility of the student, and to help him overcome the factors that impede the emotional growth until they reach emotional maturity.

The suggestions: 
1. Conducting a correlational study between the concept of recklessness and its relationship to psychological security.

2. Conducting a study similar to the current study on other samples and comparing its results with the current study.

3. Conduct a correlational study between emotional thinking and personality characteristics.

\section{References:}

[1] Abdullah, Doaa Idan (2017): Complexity style - cognitive simplification and their relationship to emotional thinking and cognitive dependency among middle school students, PhD thesis, Philosophy and Psychology, University of Baghdad.

[2] Abdul-Rahim, Muhammad Sayed, (2011): Collective Thinking Skills for High School Students, Unpublished $\mathrm{PhD}$ Thesis, Ain Shams University, College of Education, Department of Curricula and Teaching Methods.

[3] Abdul-Rahman, Ban Adnan (2014): The Evolution of suggestibility and Its Relation to the Identity Crisis of Adolescents, Unpublished $\mathrm{PhD}$ Thesis, College of Education / Ibn Rushd, University of Baghdad.

[4] Abu Hatab, Fouad and Sadiq, Amal. (2000). Educational Psychology, 6th Edition, Cairo: The Anglo-Egyptian Library.

[5] Al-Khalidi, Atallah Fuad. (2008). Guidance for Special Groups, 1st Edition, Amman: Dar Safa for Publishing and Distribution.

[6] Al-Rimawi, Muhammad Odeh and et al. (2008: General Psychology, 3rd Edition, Dar Al-Masirah for Publishing, Distribution and Printing, Amman, Jordan.

[7] Al-Shantawi, Abdul-Karim Muhammad (1990: Methods of Teaching Thinking to Children, Dar Safa, Amman, Jordan.

[8] Al-Tamimi, Mahmoud Kazem (2014): Cognitive Psychology, 1st Edition, Safaa
House for Publishing and Distribution, Amman.

[9] Alakrash, H. M., Razak, N. A., \& Bustan, E. S. (2020). The Effectiveness Of Employing Telegram Application In Teaching Vocabulary: A Quasai Experimental Study. Multicultural Education, 6(1).

[10] Damasio, A.R. (2000): Sub Cortical Brain Activity During The Feeling of SelfGenerated Emotions, Nature Neuro Science, Vol. (3).

[11] Hussein, Kodi, and Abdul-Jabbar, Nasser Muhammad. (2000). Psychological, social and academic care methods for first grades of Al-Mustansiriya University, Libya: Journal of Arts and Sciences, Issue 4, Year 4, Al-Marj University.

[12] Imam, Mustafa, Al-Ajili, Sabah, AbdulRahman, Anwar Hussein (1990): Measurement and Evaluation, University of Baghdad.

[13] Maaleeqi, Abdul Latif. (2007). Adolescence, an identity crisis or a crisis of civilization, Beirut, Lebanon, 4th edition: Publications for publication and distribution.

[14] Mehrabian, A. (2000): Beyond IQ: BroadBased Measurement of Individual Success Potential or "Emotional Intelligence" Genetic, Social, And General Psychology, Monographs, 126.

[15] Muhammad, Abu Bakr Morsi. (2002). Identity crisis in adolescence and the need for psychological counseling, Cairo: The Egyptian Renaissance Library.

[16] Qatami, Youssef. (1998). The Psychology of Classroom Learning and Teaching, Amman: Al-Shorouk Publishing House.

[17] Abdullah, Muhammad Qasim. (2003). Memory Psychology, Issue (290), Kuwait: The World of Knowledge.

[18] Alakrash, HM, Razak, NA, \& Bustan, ES (2020). The Effectiveness Of Employing Telegram Application In Teaching 
Vocabulary: A Quasai Experimental Study. Multicultural Education, 6(1).

[19] Centeno, Linda (2001): Clinical Psychologist Rid wood, new jersey. WWW.LINDACENTNO.COM

[20] Daghestani, Sanaa Issa. (1995). An experimental study on the effect of some variables on obedience behavior, an unpublished master's thesis, College of Arts, University of Baghdad.

[21] Damasio, A. (1995): Descartes Error Emotion, Reason And The Human Brain, Harper Perennial, New York.

[22] Damasio, A. (2003): Looking For Spinoza: Joy sorrow And The Feeling Brain, Orlando, Harcourt.

[23] De Bono, Edward (2001): The Six Thinking Hats, translated by Khalil Al Jayyousi, Revision by Muhammad Abdullah Al-Bailey, The Cultural Society, Abu Dhabi, United Arab Emirates.

[24] Ebel, P. L (1972) Essentials of Educational Measurement (2nd ed), Prentice-Hill, New Jersey

[25] Insko, C. (1967). Theories of Attitudes Change, Merditn Publishing company, U.S.A.

[26] Kassin, Saul \& Fein, Steven \& Markus, Hazel Rose (2011). Cognitive Dissonance Theory (The Classic version), U.S.A.

[27] Kotov, Roman, I. (2004). Suggestibility in adolescent's, stony Brook University, New York, U.S.A.

[28] Muhammad, Safaa Abdel Azim. (1999). The proposed role of a work specialist in the Friends Group to confront the phenomenon of collective suggestibility, Egypt, Journal of the Faculty of Education, Issue 3, Menoufia University.

[29] Elaf, B., \& Hussien, A. (2020). An analysis of impoliteness strategies performed by Donald Trump tweets addressing the middle east countries. Global journal of Social Science and Humanities, 1, 66-74. 